\title{
Research on Cultural Introduction Model in College English Teaching
}

\author{
Bao Mingjie $e^{1,2, *}$ \\ ${ }^{1}$ School of Foreign Languages, Jianghan University, Wuhan, China \\ ${ }^{2}$ School of Education, Stockton University, USA \\ *Corresponding author: School of Foreign Languages, Jianghan University, Wuhan, China. \\ E-mail: Mingjie.bao66@gmail.com
}

Received: March 4, 2019 Accepted: April 6, 2019 Published: April 20, 2019

doi:10.5296/ije.v11i2.14701ＵRL: https://doi.org/10.5296/ije.v11i2.14701

\begin{abstract}
Language and culture interact and restrict each other, and those two are inseparable. In college English teaching, the teaching quality and students' cultural knowledge and cultivation have been greatly improved and enhanced with the help of introducing cultural background knowledge of western countries, cultural connotation of vocabulary and cultural differences between China and Western countries. It is now available to leverage information technology platform, proceed from students' reading and writing perspective, and orient by humanistic thinking in teaching process. Those overall will contribute to the organic integration of language learning and cultural learning and lead to the new direction of college English teaching.
\end{abstract}

Keywords: College English, Cultural introduction, Teaching model 


\section{Introduction}

Language is a unique symbol of culture and a medium used to convey ideas. Language influences the development of culture, and culture also has an impact on the development of language. Those two are inseparable. Therefore, college English teaching should be connected closely with cultural background knowledge. The relationship between foreign language teaching and cultural teaching is dynamic. Cultural introduction in college English teaching is an effective method to learn a language.

\section{The Status Quo of Humanistic Education in Chinese Universities}

At present, professional sub-disciplinary education has been conducted in Chinese universities, and science and engineering majors far outweigh the humanities. Due to the excessive emphasis on STEM (science, technology, engineering, and math), humanistic education in university courses is nowadays neglected in certain extent. In recent years, in relevant research on current situation of humanistic education in China, some scholars have pointed out that humanistic education is "marginalized" and the curriculum is practicality-oriented, which leads to certain restrictions on humanistic education (Hao \& Yin, 2015). There are several aspects of its specific performance. On one hand, university education does not pay much attention to the humanities; on the other hand, students do not think humanities-related courses are as practical as STEM study. In addition, the overall atmosphere of the society also has an important impact on Chinese current education circumstance. Humanities-related literature courses are offered as elective courses in some universities, and some universities do not have corresponding credit requirements for literary assessment. The social business atmosphere and employment pressure have also made university education utilitarian. With the goal of learning technology and good employment, the enthusiasm for learning humanities-related courses is far less than that of those practical professional STEM courses. The education of college English course in China is inevitably affected in such an environment. College English is a public compulsory course aiming for graduation requirement credits. When talking about English, most students refer to qualification exams (such as CET 4 or CET 6) instead of a language for communication purpose. It is definitely important for students to acquire appropriate skills in the university, which involves students' own professional development and the needs from the entire social productivity. However, humanistic education builds for future development of human beings which enables people to understand the philosophy of life, learn to think about life, and perceive the basic moral sense of responsibility. This will also help promote the development of human culture and society which has far-reaching significance.

\section{The Urgency of Humanistic Education in College English Teaching}

The essence of education is to educate people. In the era of industrial modernization, humanity has been weakened or even replaced by industrialization. As a result, English teaching has been separated from culture for a long time, and its utilitarian role has been 
promoted exaggeratedly, leading to the lack of humanistic education. However, this is misleading for language teaching itself. The return of humanistic education is in keeping with the trend of the times and adapting to the requirements of the times.

Human beings are originally social animals, and culture is the product of human social evolution. At present, many scholars have put forward the idea that universities should be guided by humanistic education as a teaching purpose. Williams \& Burden (Williams \& Burden, 1997) pointed out the significance of humanistic approach in language teaching: "humanistic education starts with the idea that students are different, and it strives to help students become more like themselves and less like each other." During the education process, it is necessary to enable each individual to find a suitable role in society. In the current trend of the times, culture, art, and music are once again placed in a position that should be valued. The non-intellectual factor centered on the humanistic spirit is the decisive role of the competition of the comprehensive quality of contemporary talents. Higher education should not only cultivate students' professional skills, but also enable them to prepare knowledge and skills for future employment. It is also necessary to develop students' sense of morality and responsibility, and students' emotional intelligence which enables students to better engage with people. All those will help students get along with each other, better understand themselves and society, and recognize their responsibility to society which can make them have a clear career plan. Therefore, humanistic education should be re-emphasized and anticipated.

\section{The Importance of Cultural Introduction in College English Teaching}

\subsection{Requirements for Current Era}

Traditional teaching helps students to achieve high scores in various English language exams (i.e. CET 4 or CET 6). However, the lack of cultural introduction confuses students about the purpose of learning English. Students gradually lose interests and feel bored and fearful about English learning. With the development of modern society, Internet technology has been integrated into classroom teaching. Modern people's life time is fragmented, and some new online courses capture the needs of modern people and create a series of course platforms. To some extent, these new forms introduce cultural background knowledge, to cater students' preference, and attract their attention. From the perspective of college English teaching development, the emphasis on cultural introduction in classroom teaching is a sign of progress. This not only means that college English teaching returns to the culture-based language teaching model, but also means that English teaching practice is progressively advancing with the times. In today's big data era, our lives have changed a lot with the wide use of smartphones and technologies. These changes are alerting our educators that education needs to change at a similar pace. Currently, the phenomenon of being controlled by electronic products continues to occur, and the fear of human being replaced by artificial intelligence (AI) is deepening, therefore, cultural introduction is particularly important. Culture enables people to feel the interests of learning and the difference from AI. This will effectively relieve tension and find the meaning of humanity. In order to fully understand 
language, it is necessary to perceive the underlying culture for specific language.

\subsection{Requirements for Teaching Quality}

English teaching should not only allow students to master vocabulary, grammar and sentence patterns, but also enable students to understand the culture of English as a language from the inside out. Given cultural influence, many English vocabularies and expression habits are far from the expression of Chinese and some words cannot even be translated in Chinese completely. Studies have shown that cultural introduction could enhance English teaching in term of transformation in English learners' thinking (Bai, 2014).

In traditional teaching, mechanical memory of words and grammar often does not work well for the following reasons: 1) students cannot understand the source of words; 2) students cannot implicit the underlying way of thinking behind words and sentences. The introduction of culture in college English teaching begins with the supplement of background knowledge, allowing students to fundamentally understand the culture of English. This will improve the quality of teaching and contribute students to memorize on the basis of understanding.

\subsection{Requirements for Personal Culture Enrichment}

The cultural knowledge and moral cultivation of students are the key needs of today's society. The purpose of higher education is to allow students to receive the enlightenment of cultural accomplishment and to learn professional skills. This will further benefit career development and even life planning. In the meanwhile of learning language, students can also acquire the etiquette, communication skills and even the way of thinking in Western culture, which will help students form a comprehensive and balanced thinking mode. This in turn will benefit students to treat the problems and things in a more rational way. At the same time, learning Western culture helps understand Western society, engage into the life and beliefs of Westerners, and respect the existence of differences. The introduction of culture during college English teaching has a positive influence on improving students' own quality, and allows students to have the basis of cultural appreciation. By saying that, it accelerates students to become people with comprehensive quality and positive moral values, and thus achieve self-worthiness and contribute to the society, which is also the fundamental purpose of education.

\section{The Contents of Cultural Introduction in College English Teaching}

\subsection{Cultural Background Knowledge of Western Countries}

English-speaking countries, in a narrow sense, refer to countries where the first language is English; in a broad sense, it can refer to all countries where English is used as an official language. Usually, we classify English-speaking countries into Western countries, and English culture seems to represent Western culture. In fact, the scope of English culture should be narrower than that of Western culture, but the commonality lies in the profound influence of religion in Western culture. 
It is noted that the United Kingdom, the United States, Australia, and New Zealand have their own unique cultures, such as Australia's Maori culture, American Native Indian culture, etc. These are the cultural symbols of individuality in each country. Some distinct cultures have an important influence on language. For example, the Indians, as Native Americans, have their own language. Many states in the United States are named after the native Indian language, such as Ohio, Alabama, Oklahoma, etc. It is not difficult for students to find out when they are learning that the spelling of these state names is significantly different from the regular spelling of English. This is a typical case that culture directly affects language. In college English teaching, the introduction of special Western cultural knowledge will help improve the interests and enable students to understand the diversity of English culture, so that they can master the language better and deeper.

\subsection{Cultural Connotation of Vocabulary}

The revolution of vocabulary is inseparable with cultural origin, literary works, daily life, and convention. Vocabulary is not only a symbol that exists alone and the meaning of vocabulary should not be realized only through translation. In the process of college English teaching, it is critical to enable students to understand the underlying culture of the vocabulary, otherwise, it will lead to a series of controversy, even misleading. Any of those misleading reflect not only the lack of understanding of lexical culture, but also the potential problems in English teaching (Sun, 2013). In practicality-oriented college English teaching, the culture behind the vocabulary is not valued. From the cognitive learning view, passive memory neither conduces to long-term memory of vocabulary in the brain, nor stimulates students' enthusiasm in learning English. Therefore, cultural connotation of vocabulary in college English teaching should cover cultural introduction content in order to arouse the motivation of students' continuous learning.

\subsection{Cultural Differences between China and Western Countries}

The existing cultural differences can lead to misunderstanding. Chinese and Westerners have different aesthetic standards, and the same animal usually has different associations in people's minds. For example, in the view of Western culture, dogs are loyal and sensitive, and regarded as human companions and objects of love. The words related to dogs are often praised and used to describe people's lives, for example, every dog has his day. It's not surprising that animals are used to describe people. In Chinese culture, if people are compared to animals, it is usually a derogatory meaning. In addition, for bats, dragons, horses and other animals, the good and bad in Chinese and Western cultures are different. We effectively learn English well only by understanding these differences between China and Western countries. Nowadays, with the development of Internet and more transparent information, these cultural differences are gradually understood by more and more people, and people increasingly agree the coexisting differences. 


\section{The Teaching Models of Cultural Introduction in College English Teaching}

\subsection{Focusing on Student-Centered Classroom Approach}

A student-centered classroom by reversing the traditional model is called flipped classroom. This concept was proposed in 2014, and this model is the result of the development and application of information technology. In this type of classroom, there is a significant change in the spontaneity and initiative of students' learning (Phillips, 2015). Flipped classroom emphasizes the design of the classroom and allows students to learn selectively based on their own characteristics. In traditional college English course, the interaction between teachers and students are mainly led by teachers and students give feedback upon teachers' instructions. Flipped classroom mainly focuses on enhancing students' learning and achievement, and taking the initiative from the students. In order to accomplish this, teachers post short video lectures online for students to view prior to the next class session. This helps students efficiently and effectively expand in-class study and master the material through collaborative learning exercises, projects, and discussions. Students can promptly raise question to teachers, and teachers can adjust teaching content and optimize teaching materials depending on students' requirements. Besides that, students can also discuss with peers to share opinions, and initiate a learning group for mutual development.

In English classroom teaching, teachers can guide students to present their own opinions, and introduce culture learning which enables students to obtain interests. For example, in the "New Century College English" (Huang, 2017), in the dialogue of "Friends and Money Reunited", there is a sentence in the drama of Hamlet by Shakespeare, "Neither a lender nor borrower be". This sentence is different from the modern English expression habits. Teachers can intentionally have more discussion here, allow students to evaluate this expression habit. Students are able to share their opinions and use modern English to express those words. At the same time, teachers can take this opportunity to introduce the background of Shakespeare's literary works, describe the characteristics of Shakespeare's language, and even guide students to appreciate other literary works of Shakespeare. This kind of cultural introduction helps students understand the grammatical differences between old English and contemporary English, and contributes students to taste the richness and beauty of English language. The most important thing is that the whole process is led by active participation from students and this kind of learning will impress students and receive decent results.

\subsection{Leveraging Reading and Writing as a Starting Point}

In traditional college English teaching, the model of "speaking + practicing" is usually adopted. This model is a teaching model that utilizes English as a tool. Therefore, "speaking + practicing" model is not suitable for English teaching in the context of humanistic education. In order to introduce culture and humanistic education ideas, college English course should reform fundamental changes in the purpose of teaching. The accumulation of cultural background knowledge heavily depends on reading, thinking and communication of literary works. Therefore, the cooperative education model advocated by the founder of the modern educational theory of Russian should be widely and profoundly applied in college English teaching (Shemshadsara, 2012). Extracurricular reading of related literary works, 
movies, and appreciation of musicals, dramas and other artistic productions with humanistic educational purposes play an important role in accumulating students' cultural background knowledge and improving humanistic qualities (Shemshadsara, 2012).In college English teaching, teachers should appropriately add more weight into extracurricular reading, and set up extracurricular reading discussion and communication in class. Students can express emotional expressions, be good listeners, and improve cultural discernment to understand and tolerate cultural differences.

Although there may be some correlation between reading volume and reading ability, the two should be treated differently. In college English teaching, a small number of students believe that massive reading does not effectively improve their reading ability. The existence of this phenomenon shows that continuous reading is only a decisive factor of the improvement for reading ability. Another aspect of enhancing reading ability lies in the combination of reading and writing. Reading ability and writing ability are complementary and have the characteristics of mutual transformation. Reading is the process of absorbing information, while writing is the process of conveying information. During the writing process, it can reflect some questions, such as the accumulation of vocabulary, the speed of reading, and the ability of converting Chinese and English thinking. In native language learning process, students improve their writing skills by reading high quality articles and imitating their writing skills. In the study of English language, it is favorable to follow the similar procedure, guide students to read the excerpts of famous articles, and explain its framework and rhetorical techniques in writing. This allows students to imitate writing and peer-review for mutual benefits.

In addition, extracurricular reading should also be updated with the times. Teachers frequently set priority of classical works such as Shakespeare, Dickens, and Hugo for traditional reading. These literary works certainly reflect an era and have far-reaching significance. However, with the change of the times, the culture has also changed. Therefore, in the meanwhile of recommending classical literature, we should also pay attention to the development of today's culture, keep pace with the times, and constantly update. The winner of the Nobel Prize in Literature in 2016 is Bob Dylan, a musician. The inspiration for college English teaching is that reading includes, but is not limited to textual presentations, as well as music, movies, dramas, and musicals. All should belong to the category of appreciation. The choice of materials for college English teaching should not only be limited to text materials but also include various forms of reading materials to activate students' interests in learning. Teachers can organize students to enjoy high performance English movies and musicals based on their needs, so that students can understand the feeling, gain mental energy and improve English level.

\subsection{Using the Information Platform as a Carrier}

Information technology makes it visible to view teaching materials on the Internet platform. College English teaching can fully leverage network to share resources and expand the learning platform. There are many learning platforms offering online courses, and a new educational ecological environment called mass open online courses (MOOCS) has been 
newly introduced (Milligan, 2016).

Compared with traditional classroom teaching, MOOCS have some obvious advantages. One of the characteristics of MOOCS is that it gives students the opportunity to plan study time to best fit their schedule. For example, a first year student majoring in architect at Peking University in China can choose computer science courses provided by Stanford University at his spare time. This feature is not available in traditional classrooms. The scope and depth of the course can be flexibly adjusted according to the students' own needs. Another feature of MOOCS is that students can interact with teachers and other students remotely through online platform, and use online chat tools to ask questions simultaneously. The online chat tool can also be an online service person or artificial intelligence robot. In addition, real-time big data on online platform offers students to access the latest learning progress reports at any time, therefore, students can discover their learning advantages, understand existing deficiencies, and adjust learning style in a timely manner.

With the rise of MOOCS in recent years, it has been pushed to the forefront by the times and the future prospects and trends of the MOOCS will be a challenge for the traditional classroom.

\subsubsection{Cultural Introduction through MOOCS}

The duration of a single video in MOOCS is usually no more than 30 minutes, so the knowledge points presented in each video are mainly focused on few bullet points. In MOOCS, relevant cultural background knowledge points presented in the video can be smoothly introduced which can effectively raise students' interests to learn. Taking the oral English class as an example, teachers usually start with a story from a typical British and American family as the teaching content and organically introduce cultural differences between China and Western countries. This can gradually enhance students' ability to communicate and build their self-confidence. This form of classroom is to allow students to participate in learning with interest. It is a supplement to face-to-face classroom teaching and can help achieve comprehensive English learning.

\subsubsection{Cultural Introduction through Communication Platform}

The interaction experience between human and computer is not a strange concept at this stage. The development of artificial intelligence (AI) has made human-computer interaction popular in people's daily life. In current big data era, students can not only interact with people, but also communicate with AI robot. For example, when students encounter problems in their studies, they can ask either teachers in class or search answers from Internet. In the process of asking and answering questions, organic cultural introduction can improve the quality of interactive communication. As a teacher, it is available to utilize the information platform to share English language and culture-related posts periodically, and add self-understanding and judgment simultaneously for students to read and review. In addition, teachers can also guide students to search relevant information in order to solve problems. This can lead students to focus on culture-related problems, and enable students to spontaneously read relevant materials to achieve the goal for cultural introduction. 
On the other hand, the online platform is also loaded with all kinds of information, and this requires students to improve their discernment and adopt only effective information according to their needs. Therefore, during teacher-student interaction stage, teachers have the responsibility to direct students how to identify and extract useful information, and improve students' own judgment.

\section{Conclusion}

Practicality-oriented college English teaching has exposed a series of problems. The lack of humanistic education urges the necessity and importance of cultural introduction in college English teaching. The emphasis on culture is being used as a sign for the time progress. In college English teaching, the introduction of cultural background knowledge of western countries, cultural connotation of vocabulary and cultural differences between China and Western countries can improve teaching quality of college English and enhance students' cultural knowledge and cultivation. The hardcore of cultural introduction is to stimulate and maintain students' enthusiasm for English learning, and mobilize spontaneity of students' English learning. Therefore, the new direction for college English teaching should involve information technology platform, stand from students' perspective, guide by humanistic thinking, enhance students' humanistic qualities, and make organic integration of language learning and cultural learning.

\section{Acknowledgement}

The research is supported by Research and Planning Fund for Education and Sciences Program of Education Department in Hubei Province (2017ZA011).

\section{References}

Bai, W. (2014). Culture Introduction and Cross-Cultural Communication Competence in College English Teaching. Studies in Literature and Language, 9(1), 90-93. http://dx.doi.org/10.3968/5305

Hao, X., \& Yin, Z. (2015). College English Teaching Reform in China: An Orientation toward ESP. International Journal of English Language Teaching, 2(2), 77-86. http://dx.doi.org/10.5430/ijelt.v2n2p77

Huang, Y. (2017). New Century College English-Learning to Read: An English Reading Course. Shanghai: Shanghai Foreign Language Education Press.

Milligan, S. (2016). Understanding Learning and Learning Design in MOOCs: A Measurement-Based Interpretation. Journal of Learning Analytics, 3(2), 88-115. http://dx.doi.org/10.18608/jla.2016.32.5

Phillips, C. (2015). The Use of Flipped Classrooms in Higher Education: A Scoping Review. 
The Internet and Higher Education, 25(C), 85-95. http://dx.doi.org/10.1016/j.iheduc.2015.02.002

Shemshadsara, Z. G. (2012). Developing Cultural Awareness in Foreign Language Teaching. English Language Teaching, 5(3), 95-99. http://dx.doi.org/10.5539/elt.v5n3p95

Sun, L. (2013, February). Culture Teaching in Foreign Language Teaching. Theory and Practice in Language Studies, 3(2), 371-375. http://dx.doi.org/10.4304/tpls.3.2

Williams, M., \& Burden, R. (1997). Psychology for Language Teachers A Social Constructivist Approach. Cambridge: Cambridge University Press.

\section{Copyright Disclaimer}

Copyright for this article is retained by the author, with first publication rights granted to the journal.

This is an open-access article distributed under the terms and conditions of the Creative Commons Attribution license (http://creativecommons.org/licenses/by/3.0/). 